\title{
Ferrofluid plug as valve and \\ actuator for whole-cell PCR on chip
}

Khoi Seng Lok, Yien Chian Kwok, Peter Peng Foo Lee, and Nam-Trung Nguyen

\author{
K. S. Lok, Y. C. Kwok, P. P. F. Lee \\ National Institute of Education, \\ Nanyang Technological University, \\ 1 Nanyang Walk, \\ Singapore 637616, Singapore \\ E-mail: peter.lee@nie.edu.sg
}

N.T. Nguyen

School of Mechanical and Aerospace Engineering,

Nanyang Technological University,

50 Nanyang avenue,

Singapore, 639798, Singapore

E-mail: mntnguyen@ntu.edu.sg

Keywords: whole-cell PCR, magnetically actuated, PCR microchip, lab-on-a-chip, ferrofluid.

\section{Abstracts}

Ferrofluid plug was first used as valve and actuator to circumvent the evaporation of aqueous fluid in LOC. Moreover, this dynamic plug catered for aqueous fluid expansion during its heating in the microchannel. Whole-cell polymerase chain reaction (PCR) protocol was successfully implemented in a magnetically actuated closed-loop PCR microchip system. Here, 
the ferrofluid plug was used to reduce the evaporation of the PCR sample in the thermal lysis step. A whole-cell PCR model was used to demonstrate this concept. The DNA plasmid, pUC19, was transformed into $\mathrm{DH} 5 \alpha$ competent cells. Primer pairs were designed to amplify region of interest in pUC19. The transformants were cultured and selected. Whole-cell PCR was performed on intact bacteria to screen for the presence of pUC19, containing the region of interests. Serial dilutions demonstrated the limit of detection for this system to be four bacteria cells. PCR amplifications were verified with regular thermocyclers and results were comparable. 


\section{Introduction}

Ferrofluids consist of magnetite particles $\left(\mathrm{Fe}_{3} \mathrm{O}_{4}\right)$ with a diameter of $10 \mathrm{~nm}$ dispersed in water or oil. The fluids display paramagnetic properties and have been used as an actuator for micropumps [1-5], microvalves [1], micromixers [6] and nanocytometry [7]. Ferrofluids can be pumped effectively in closed-channel geometries both in the macroand micro-scales using spatially travelling, and sinusoidal time-varying magnetic fields

[8]. Moreover, ester oil-based ferrofluid is immiscible with water. Hence, this fluid may also serve as a covering oil (similar role as mineral oil) to prevent the evaporation of water. An external magnet may also be used to hold the ferrofluid in place, which in turn restrains the aqueous medium in a microchannel. Moreover, this dynamic plug caters for the expansion of fluid during heating.

Whole-cell PCR is a variant PCR technique which involves direct addition of intact bacteria cells to PCR reaction. Whole-cell PCR is usually implemented in integrated PCRcapillary electrophoresis microchips [9-11] or bacteria cells captured system [12-14]. The thermal lysis step was important to lyse the bacterial cell, to release and denature the genomic DNA template, and to inactivate the nuclease protein. Initial thermal lysis in these devices was realized at $\approx 94^{\circ} \mathrm{C}$ for a period of holding, prior to PCR thermal cycling. Prolonged heating of a miniature sample may result in rapid reduction of its volume, when it is not well-handled. On top of this, heated fluid also expands rapidly in microchannel.

Here, a novel technique of using oil-based ferrofluid to circumvent the evaporation of aqueous samples was introduced in LOC to resolve the issues. This dynamic plug held the sample in place during heating in the thermal lysis step, allowing whole-cell polymerase chain reaction (PCR) to be implemented in the magnetic actuation for PCR 
microchip system $[2,3,15]$. The ferrofluid also served as the actuator to propel the PCR mixture along the circular closed-loop microchannel through different temperature zones. In the initial publication, the PCR protocol only consisted of thermal steps of denaturation, annealing and extension, without the pre-denaturation step [2]. This truncated PCR protocol was widely adapted in most PCR microchip system $[16,17]$. Previous applications dealt with treated DNA samples for standard PCR. However, preliminary studies showed that the thermal protocol affected whole-cell PCR dramatically. Without this pre-denaturation step, the bacteria were not properly lysed. On the other hand, the addition of this extra thermal step in the thermal cycling profile rendered undesirable evaporation of the PCR sample. Moreover, the sample volume of $5 \mu \mathrm{L}$ was small, leaving a limited volume for further downstream analysis. Hence, the addition of the pre-denaturation step was necessary for whole cell PCR to work on the microchip system. The ferrofluidic plug was an important component to facilitate the heating process of the sample.

\section{Experimental}

\subsection{PCR samples preparations}

The bacteria cells were prepared by transforming the plasmid pUC19 DNA cloning vector into DH5 $\alpha$ competent cells (Invitrogen, CA, US), according to the manufacturer's protocol. LB medium and agar were prepared according to manufacturer's instructions (1st Base, Singapore). During this preparation, $100 \mu \mathrm{g} / \mathrm{mL}$ of ampicillin was added to the medium and agar to allow only pathogen with ampicillin resistance gene to grow. 
A sample of $100 \mu \mathrm{L}$ of the transformant products was plated onto LB plate with $100 \mu \mathrm{g} / \mathrm{mL}$ ampicillin, incubated overnight at $37^{\circ} \mathrm{C}$, to check for transformation efficiency. The rest of the products were added into a culture tube containing $10 \mathrm{~mL}$ of LB medium with $100 \mu \mathrm{g} / \mathrm{mL}$ ampicillin. They were cultured overnight at $37^{\circ} \mathrm{C}, 200 \mathrm{rpm}$ in the incubator. The cell culture of $\approx 6 \times 10^{5}$ cells $/ \mathrm{mL}$ was then serially diluted by 10 -fold with $\mathrm{LB}$ medium with $100 \mu \mathrm{g} / \mathrm{mL}$ ampicillin. A sample of $100 \mu \mathrm{L}$ of the serial diluted cell cultures from 0 to $6 \times 10^{5}$ cells $/ \mathrm{mL}$ were plated onto LB plate with $100 \mu \mathrm{g} / \mathrm{mL}$ ampicillin for colony count, to find out the exact amount of cells that it contained. Excess cell cultures were stored at $4^{\circ} \mathrm{C}$ temporarily and were thrown away after 3 days.

Primers pairs A, B and C were designed to prime out DNA base pair (bp) size of 209, 480 and 711 respectively in the pUC19 (GenBank accession L09137), using primer-blast. All primer sets had the same forward primer, 5'- TACCGCGAGACCCACGCTCA-3'. Reverse primer of set A, B and C were 5'-CGACGAGCGTGACACCACGA-3', 5'-ACGCCGGGCAAGAGCAACTC-3' and 5'-TCCGTGTCGCCCTTATTCCCT-3' respectively. These primers were synthesized by and purchased from 1st Base (Singapore).

Go Taq Hot Start Green Master Mix, nuclease-free water, Bovine Serum Albumin (BSA) were purchased from Promega (Fitchburg, Wisconsin). The final PCR mixture was prepared with $0.2 \mu \mathrm{M}$ of forward and reverse primer pairs (A, B or C), 1× Go Taq Hot Start Green Master Mix and $1 \mu \mathrm{g} / \mu \mathrm{L}$ of BSA. A sample of $1 \mu \mathrm{L}$ of cell cultures with known cell numbers were added to per $10 \mu \mathrm{L}$ of PCR master mix. The mixture was top up with nuclease-free water.

\subsection{PCR in microchip system}

Whole-cell PCR was then performed in the magnetically actuated circular closed-loop PCR microchip system. $2 \mu \mathrm{L}$ of ester oil-based ferrofluid and $5 \mu \mathrm{L}$ of prepared PCR 
mixture were loaded onto the access port of this microchip. The samples were loaded into the microchip by centrifuge, Fig. 1. This microchip design, loading and retrieval technique was reported in another paper [18]. This microchip was fabricated using polymethyl methacrylate (PMMA) by laser ablation and thermal bonding. The chip measured $25 \mathrm{~mm}$ in width, $42 \mathrm{~mm}$ in height and $1.05 \mathrm{~mm}$ in thickness. The circular PCR channel had a diameter of $20 \mathrm{~mm}$, a width of $0.375 \mathrm{~mm}$ and height of $0.3 \mathrm{~mm}$, and a resultant volume of $\approx 7 \mu \mathrm{L}$. Silicon oil was used to cover the access holes of the microchip to prevent evaporation of the PCR mixture. This loaded microchip (Fig. 1) was then placed on the microchip system for PCR amplification [2, 19]. An external rotary permanent magnet guided the ferrofluid plug along the circular channel. This plug, in turn, propelled the PCR mixture along the various discrete temperature zones. These zones were formed by the heater unit which consisted of three blocks, Fig. 2. The temperature could be set independently in each block. The thermal lysis/denaturation step was included in the thermal cycling profile for whole-cell PCR.

In the thermal lysis step, the ferrofluid plug was held as shown in Fig. 2(a). The block with the ferrofluid plug above it, was set to be $60^{\circ} \mathrm{C}$; the other two blocks with the PCR mixture above it were set to be $94^{\circ} \mathrm{C}$. The ferrofluid plug was held in place by the stationary magnet. The ferrofluid in the microchannel could act as an actuator in a pump or microvalve. Here, the ferrofluid plug was held in place to block the opening of the circular channel reducing the evaporation of the PCR mixture. The duration required for thermal lysis was investigated and will be discussed later.

Next, the heater unit was set to cater for denaturation $\left(94^{\circ} \mathrm{C}\right)$, annealing $\left(60^{\circ} \mathrm{C}\right)$ and extension thermal steps $\left(72^{\circ} \mathrm{C}\right)$. The external rotary magnet actuated the ferrofluid plug in the circular channel. Since the oil-based plug was immiscible with an aqueous PCR mixture, the mixture was propelled by the movement of this plug along the channel 
through the discrete temperature zones, Fig. 2(b). One thermal cycle in this system was 36 seconds and the total runtime was 15 minutes for 25 cycles. At the final extension step, one of the blocks with the ferrofluid plug above it, was set to be $60^{\circ} \mathrm{C}$, the other two blocks were set to be $72^{\circ} \mathrm{C}$, Fig. 2 (c). This step allows the final extension for 3 minutes. During sample retrieval, the microchip was placed inverted in a clean sterile 50-mL centrifuge tube and centrifuged. The samples dropped onto the bottom of the tube. The oil-based ferrofluid and PCR mixture are immiscible, so the PCR mixture can be removed easily by a pipette. An external magnet can also be used to separate the two fluids.

To investigate how the duration of the thermal lysis step affects whole-cell PCR in this microchip system, $0.5 \mu \mathrm{L}$ of the bacteria cell culture, containing 384 bacteria cells was added into $5 \mu \mathrm{L}$ of PCR mixture for PCR DNA amplification. Primer pair B was used. The initial thermal lysis step was set to be $15,10,5,3,1$ or 0 min at $94^{\circ} \mathrm{C}$. The subsequent parameters for thermal cycling were, as mentioned eariler. The products were analysed on $0.8 \%$ agarose gel electrophoresis. The expected 480 -bp DNA band was considered as positive result.

To find out the lowest number of bacteria cells that whole-cell PCR would work in this microchip system, 10 -fold serial dilutions were performed on the original cell culture. An amount of $0.5 \mu \mathrm{L}$ of the cell culture containing varying number of cells, from 0 to $\approx 300$, was added to the PCR mixture. The samples were loaded onto the circular microchip. PCR was performed using primer pairs A, B and C individually. The products were analysed using gel electrophoresis. The UV gel image was exported and further analysed. 209, 480 and 711-bp size DNA product were expected from the PCR amplification, using primer pair A, B and C respectively. Exact numbers of bacteria cells 
used in the experiment were counted by plating. These experiments were repeated on a commercial thermocycler for comparison.

To understand how the microchip system performed when compared to regular thermocycler, the experiments were repeated on a commercial thermocycler system. In this experiment, $20 \mu \mathrm{L}$ of PCR mixture was prepared. A volume of $2 \mu \mathrm{L}$ of bacteria culture was included in this mixture. GeneAmp PCR system 9700 was purchased from Life Technologies (USA) and was used for the comparison. The thermal cycling profile was set to initial denaturation $\left(94^{\circ} \mathrm{C}\right)$ for $3 \mathrm{~min}, 25$ cycles of denaturation $\left(94^{\circ} \mathrm{C}\right)$, annealing $\left(60^{\circ} \mathrm{C}\right)$ and extension $\left(72^{\circ} \mathrm{C}\right)$ for $30 \mathrm{~s}$ each, and final extension step $\left(72{ }^{\circ} \mathrm{C}\right)$ for 5 min. The products were kept at $25^{\circ} \mathrm{C}$. PCR amplifications were conducted. After the PCR, $10 \mu \mathrm{L}$ of the PCR mixture were loaded and analysed using gel electrophoresis. The band intensities were normalized to the equivalent $5 \mu \mathrm{L}$, to compare with the results obtained from the microchip system.

\section{Results and discussion}

\subsection{Thermal lysis step}

The duration of thermal lysis step, from 0 to 15 mins, was investigated to understand its effect on the whole-cell PCR. No DNA band was observed in the gel image for duration of the thermal lysis step at $1 \mathrm{~min}$ and below, implying that there was no PCR amplification. Apparently, insufficient time was given to activate the hot start polymerase or to lyse the cells. Clear DNA band were observed for the duration of $3 \mathrm{~min}$ and above. This showed that a successful PCR was performed. Long duration of thermal lysis step with 5 minutes and above, evaporation of the PCR mixture reduced the total 
volume left. The volume left behind could be as low as $3 \mu \mathrm{L}$ after 15 minutes. Hence, in the later experiments, effort was made to position the ferrofluid plug in the microchip as shown in Fig. 2(a) and the duration of the thermal lysis step was set to be three minutes.

\subsection{Detection limit for microchip system}

The detection limit for this microchip system was explored by doing whole-cell PCR on serially diluted cultures. Fig. 3(a) shows the gel image obtained from one of the five repeated experiments. The DNA products are successfully detected down to four bacteria cells. This number of the cells was calculated by using colony count on LB plate with $100 \mu \mathrm{L}$ of the bacteria culture.

The band intensity of the DNA products were calculated and compared against the number of cells. This relationship was then plotted in Fig. 3(b). Band intensity of the DNA increased with the number of cells being put in the PCR mixture. This band intensity of the DNA products increased linearly from 0 to 40 cells. These findings were similar to Lagally et al.'s work [11]. Since it is not a practice to count the number of bacteria in the culture or blood sample, by the means of PCR amplification, this aspect is not further explored. The band intensity became saturated with higher amount of cells. Given that the nature of PCR is an exponential amplification, the band intensity should increase exponentially with different amount of starting material. But this increase in band intensity is also limited by the amount of PCR reagents used. As expected, set A have a smaller DNA fragment size compare to set B and C, corresponding to lower band intensities. For all three primer pairs, the limit of detection was down to four bacteria cells. This was comparable to Lagally et al.'s work, in which 2-3 cells can be detected in each PCR run [11]. 


\subsection{Comparison with thermocycler system}

The whole-cell PCR results obtained from the microchip system was compared to the thermocycler. Fig. 3(c) shows the number of cells against band intensities of the DNA product. The graph profile obtained for thermocycler system (Fig 3(b)) was comparable to the microchip system (Fig. 3(c)). The lower limit of detection for the thermocycler system was two cells, which was lower than the microchip system. It is normal for the detection limit of the thermocycler system to be lower. This is due to the amount of sampling volume in thermocycler system $(2 \mu \mathrm{L})$ is four times larger than the microchip system. Larger sampling volume allows higher probability and chances to capture a physical cell from a diluted cell culture in the tube.

\subsection{Advantages of microchip system}

Whole-cell PCR allows immediate PCR of intact bacterial cell without the needs of DNA extraction. The run-time for each whole-cell PCR runs in this microchip system was around 20 min for 24 thermal cycles which was comparable or shorter than previous works[9-11] and conventional thermocycler system. The sample throughput in this report was a single sample run, but can be made to accommodate up to four or more parallel sample runs [3]. Further work may involve integration of bacteria capturing system to filter the bacteria from human serum before whole-cell PCR is performed.

\subsection{Advantages of ferrofluid plug}

The ester oil-based ferrofluid plug at the opening of the circular channel of the microchip reduced the effect of the evaporation of the PCR mixture, Fig. 2(a). If the plug was positioned otherwise, the amount of product being retrieved was none or too little to be used for gel electrophoresis. The use of silicon oil to cover the access hole of the microchip was insufficient to prevent the evaporation of the PCR mixture, because the 
temperature involved was $94^{\circ} \mathrm{C}$, which was close to the boiling point of water, and the duration of heating was relatively long. A solid plug such as a rubber plug cannot be used in replacement. The plug may be too big to fill into the channel or will loosen itself due to heating. Furthermore, elastic polymer material such as PDMS may also melt due to heating.

The oil-based ferrofluid plug served a very important role in preventing the evaporation of the samples in whole-cell PCR for this microchip system. The plug held the sample in place and allowed prolonged heating in thermal lysis step to occur. Majority of the precious samples would have been lost to evaporation without this plug. This generic concept of using ferrofluid plug as a valve to contain the fluid that requires heating may be applicable for other future LOC devices. Ferrofluids can maintain its performance at temperature of $150^{\circ} \mathrm{C}$ continuously or $200^{\circ} \mathrm{C}$ intermittently. The pressure held by the ferrofluid plug restrains the water from evaporating in the microchannel. More importantly, this plug is dynamic and can cater for the expansion of fluid during heating. Moreover, an external magnet can also be used to separate these fluids easily. The ferrofluidic pumping concept can be improved by using a travelling magnetic field [20] or a stepper micropump [21], instead of the current external rotatory magnet. This may allow better control of the ferrofluidic plug in the microchannel. 


\section{Conclusions}

Ferrofluid was made to form a dynamic plug to contain the samples in the microchannel during the thermal lysis step, preventing excess evaporation of the sample. The magnetically actuated circular closed-loop microchip system was demonstrated to be proficient of performing whole-cell PCR rapidly. The limit of detection was down to four cells. The band intensities from PCR were comparable to a regular thermocycler. Runtime was shorter or comparable to other microchip and conventional thermocycler system. Overall, the microchip system shows a robust performance for whole-cell PCR. 


\section{References}

[1] H. Hartshorne, C.J. Backhouse, W.E. Lee, Ferrofluid-based microchip pump and valve, Sensors and Actuators B: Chemical, 99 (2004) 592-600.

[2] Y. Sun, Y.C. Kwok, N.T. Nguyen, A circular ferrofluid driven microchip for rapid polymerase chain reaction, Lab Chip, 7 (2007) 1012-1017.

[3] Y. Sun, N.T. Nguyen, Y.C. Kwok, High-throughput polymerase chain reaction in parallel circular loops using magnetic actuation, Anal Chem, 80 (2008) 61276130.

[4] F. Schneider, D. Hohlfeld, U. Wallrabe, Miniaturized electromagnetic ferrofluid actuator, in: 10th International Conference on New Actuators, Actuator, Bremen, Germany, 2006, pp. 289-292.

[5] A. Hatch, A.E. Kamholz, G. Holman, P. Yager, K.F. Böhringer, A Ferrofluidic Magnetic Micropump, J. microeletromech sys. , 10 (2001) 215-221.

[6] D.-W. Oh, J.S. Jin, J.H. Choi, H.-Y. Kim, J.S. Lee, A microfluidic chaotic mixer using ferrofluid, Journal of Micromechanics and Microengineering, 17 (2007) 2077.

[7] A.R. Kose, H. Koser, Ferrofluid mediated nanocytometry, Lab on a Chip, 12 (2012).

[8] L. Mao, H. Koser, Towards ferrofluidics for $\mu$-TAS and lab on-a-chip applications, Nanotechnology, 17 (2006) S34.

[9] L.C. Waters, S.C. Jacobson, N. Kroutchinina, J. Khandurina, R.S. Foote, J.M. Ramsey, Multiple sample PCR amplification and electrophoretic analysis on a microchip, Anal Chem, 70 (1998) 5172-5176. 
[10] L.C. Waters, S.C. Jacobson, N. Kroutchinina, J. Khandurina, R.S. Foote, J.M. Ramsey, Microchip Device for Cell Lysis, Multiplex PCR Amplification, and Electrophoretic Sizing, Analytical Chemistry, 70 (1998) 158-162.

[11] E.T. Lagally, J.R. Scherer, R.G. Blazej, N.M. Toriello, B.A. Diep, M. Ramchandani, G.F. Sensabaugh, L.W. Riley, R.A. Mathies, Integrated Portable Genetic Analysis Microsystem for Pathogen/Infectious Disease Detection, Analytical Chemistry, 76 (2004) 3162-3170.

[12] A.F. Sauer-Budge, P. Mirer, A. Chatterjee, C.M. Klapperich, D. Chargin, A. Sharon, Low cost and manufacturable complete microTAS for detecting bacteria, Lab on a Chip, 9 (2009) 2803-2810.

[13] K.-Y. Hwang, H.-K. Lim, S.-Y. Jung, K. Namkoong, J.-H. Kim, N. Huh, C. Ko, J.-C. Park, Bacterial DNA Sample Preparation from Whole Blood Using Surface-Modified Si Pillar Arrays, Analytical Chemistry, 80 (2008) 7786-7791.

[14] K.-Y. Hwang, S.-Y. Jeong, Y.-R. Kim, K. Namkoong, H.-K. Lim, W.-S. Chung, J.-H. Kim, N. Huh, Rapid detection of bacterial cell from whole blood: Integration of DNA sample preparation into single micro-PCR chip, Sensors and Actuators B: Chemical, 154 (2011) 46-51.

[15] Y. Sun, Y.-C. Kwok, P. Foo-Peng Lee, N.-T. Nguyen, Rapid amplification of genetically modified organisms using a circular ferrofluid-driven PCR microchip, Analytical and Bioanalytical Chemistry, 394 (2009) 1505-1508.

[16] L.J. Kricka, P. Wilding, Microchip PCR, Anal Bioanal Chem, 377 (2003) $820-825$.

[17] Y. Sun, Y.C. Kwok, Polymeric microfluidic system for DNA analysis, Analytica Chimica Acta, 556 (2006) 80-96. 
[18] K.S. Lok, Y.C. Kwok, N.-T. Nguyen, Sample loading and retrieval by centrifugation in a closed-loop PCR microchip, Microchimica Acta, 176 (2012) 445-453.

[19] K.S. Lok, P.P.F. Lee, Y. Kwok, N.-T. Nguyen, Nested PCR in magnetically actuated circular closed-loop PCR microchip system, Microchimica Acta, 1-7. [20] L. Mao, S. Elborai, X. He, M. Zahn, H. Koser, Direct observation of closedloop ferrohydrodynamic pumping under traveling magnetic fields, Physical Review B, 84 (2011) 104431.

[21] N.-T. Nguyen, M.-F. Chai, A Stepper Micropump for Ferrofluid Driven Microfluidic Systems, Micro and Nanosystems, 1 (2010) 17-21. 


\section{List of figures and tables}

Fig. 1. Loaded PCR microchip.

Fig. 2. Protocol for whole-cell PCR: (a) Thermal lysis. (b) DNA amplification (c) Final Extension.

Fig. 3. Results of whole-cell PCR: (a) UV gel image obtained from whole-cell PCR in microchip system. A, B and C represents primer pairs A, B and C; L: 1 kb DNA ladder. 1, 2, 3,4 and 5 contains 4, 19, 38, 192 and 384 cells accordingly. Number of cells in the PCR mixture against band intensity of the DNA products obtained from whole-cell PCR in microchip system (b) and thermocycler system (c). The expected products of set A, B and $C$ are $209,480,711$-bp respectively. The image or graph is a representative of five experimental runs. 


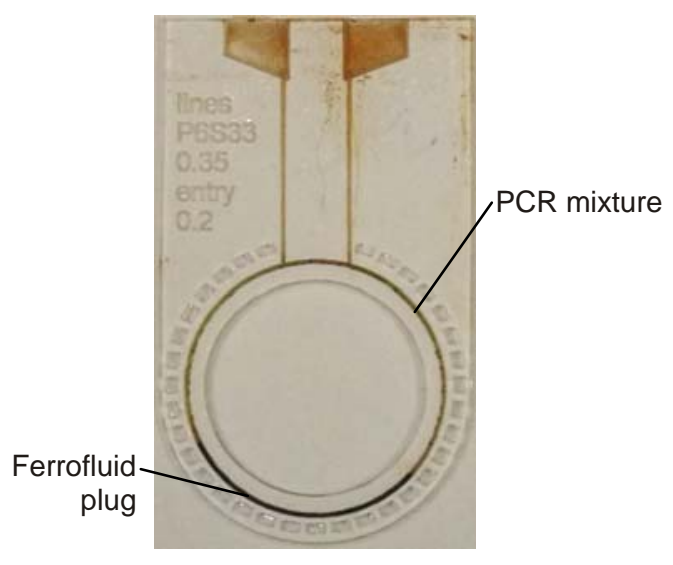

Fig. 1


Fig. 2 


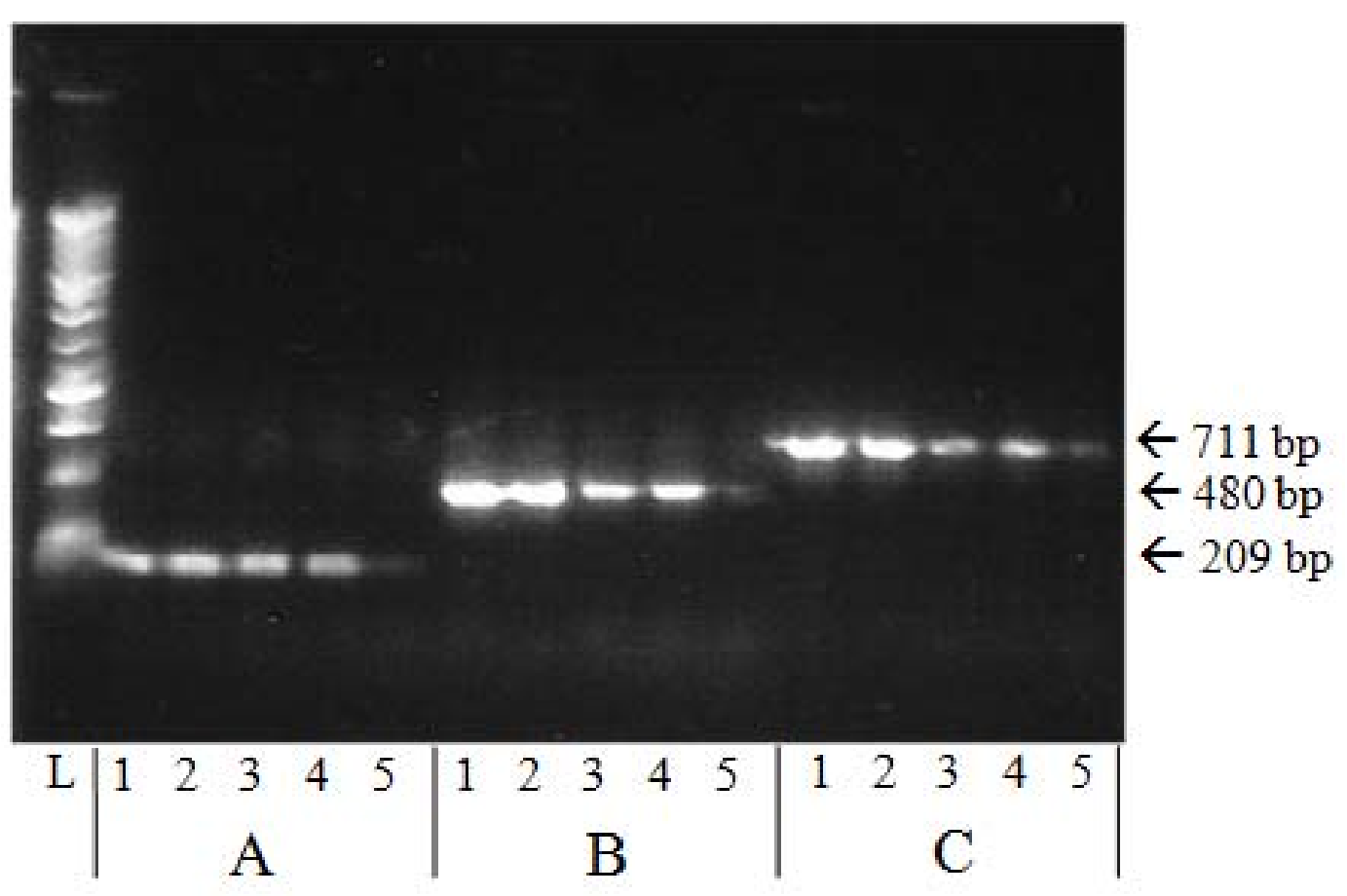

(a)



(b) 


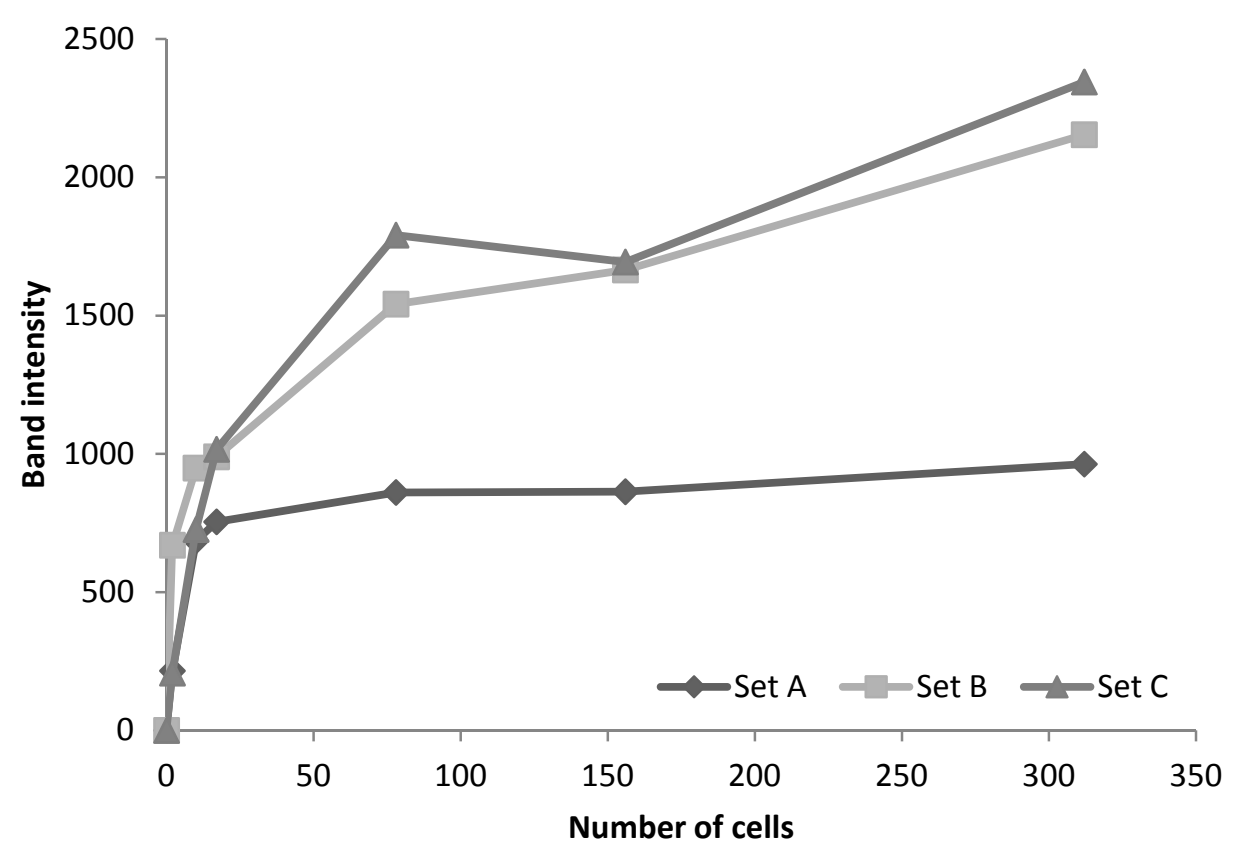

(c)

Fig. 3 


\section{Vitae}

Khoi Seng Lok received the B. Sc from the School of Biological Science, Nanyang Technological University. Upon graduation, he worked as Software Test Engineer in Applied Biosystems and Research Scientist in Singapore General Hospital. He is currently a research student at National Institute of Education, Nanyang Technological University. His research interests include human diseases, drug discovery, and clinical diagnostic devices.

Yien Chian Kwok received his PhD in Chemistry in 2001 from Imperial College, London under the supervision of Professor Andreas Manz. At Imperial College, he explored a novel detection methodology, named Shah Convolution Fourier transform (SCOFT), for ultra-sensitive detection in microfluidic devices. Now he is Assistant Professor of Chemistry at National Institute of Education, Nanyang Technological University. His current research interests include the fabrication and use of plastic microfluidic devices for DNA and chemical analyses.

\section{Peter Peng Foo Lee [}

\section{]}

Nam-Trung Nguyen received his Dip-Ing, Dr.Ing and Dr.Ing Habil degrees from Chemnitz University of Technology, Germany, in 1993, 1997, and 2004, respectively. In 1998, he worked as a postdoctoral research engineer in the Berkeley Sensor and Actuator Center (UC Berkeley, USA). He is currently an Associate Professor with the School of Mechanical and Aerospace Engineering of the Nanyang Technological University in Singapore. His research is focused on microfluidics and instrumentation for biomedical applications. The second edition of his book "Fundamentals and Applications 
of Microfluidics" and the recent books "Micromixers" and "Nanofluidics" were published in 2006, 2008 and 2009, respectively. 